\title{
PERBANDINGAN PENGGUNAAN MODEL PEMBELAJARAN RECIPROCAL TEACHING DENGAN MODEL PEMBELAJARAN STAD DILIHAT DARI HASIL BELAJAR IPS
}

\author{
Kartona Asnosus Ferpin \\ e-mail: fherpin22@gmail.com \\ Rusno \\ e-mail: rusno@unikama.ac.id \\ Naim
}

(Program Studi Pendidikan Ekonomi, Fakultas Ekonomika dan Bisnis, Universitas Kanjuruhan, Malang)

\begin{abstract}
This study aims to determine the differences in social studies learning outcomes between students who use the Reciprocal Teaching learning model and the STAD learning model) in class VII SMP 17 Malang. The research sample was taken from 2 classes from 8th grade VII of SMP Negeri 17 Malang totaling 68 students divided into two experimental classes I and experimental class II, the first class was taught using the Reciprocal Teaching learning model and the second class was taught using the STAD learning model. This type of research is Quasi Experiment with design. Data were analyzed using prerequisite test analysis techniques and hypothesis testing with the help of the SPSS 16.00 for windows program. The results of the calculation of the value of tcount 3.046 with Sig .003. by determining the table of t values with the formula $d f(n-2)$. The value of $d f=66$, so that rtable $=1.6682$. Based on a significance level of $5 \%$, the rcount result was 3,046> rtable 1.6682. so it can be said that Ha was accepted and Ho was rejected. So based on the results of the analysis of the data it can be concluded that there was a significant difference in the use of the Reciplrocal Teaching learning model with the STAD learning model seen from the learning outcomes of Grade VII students of SMP Negeri 17 Malang.
\end{abstract}

Keywords : Reciprocal Teaching, STAD , Learning Outcome..

\begin{abstract}
Abstrak: Penelitian ini bertujuan untuk mengetahui perbedaan hasil belajar IPS antara siswa yang menggunakan model pembelajaran Reciprocal Teaching dengan model pembelajaran STAD) pada kelas VII SMP Negeri 17 Malang. Sampel penelitian diambil 2 kelas dari 8 kelas VII SMP Negeri 17 Malang yang berjumlah 68 peserta didik yang terbagi menjadi dua kelas eksperimen I dan kelas eksperimen II, kelas pertama diajar menggunakan model pembelajaran Reciprocal Teaching dan kelas kedua diajar menggunakan model pembelajran STAD. Jenis penelitian adalah Quasi Eksperimen dengan desain. Data dianalisis dengan menggunakan teknik analisis uji prasyarat dan uji hipotesis dengan bantuan program SPSS 16.00 for windows. Hasil perhitungan nilai thitung 3.046 dengan Sig .003. dengan menentukan tabel nilai-nilai t dengan rumus $d f(n-2)$. Nilai $d f=66$, sehingga rtabel $=1.6682$. berdasarkan taraf signifikansi $5 \%$ ditemukan hasil rhitung 3.046 > rtabel 1.6682. sehingga dapat dikatakan bahwa Ha diterima dan Ho ditolak. Jadi berdasarkan hasil analisis data tersebut dapat disimpulkan bahwa terdadapat perbedaan yang signifikan penggunaan model pembelajaran Reciplrocal Teaching dengan model pembelajaran STAD dilihat dari hasil belajar siswa kelas VII SMP Negeri 17 Malang.
\end{abstract}

Kata kunci : Reciprocal Teaching, STAD, Hasil Belajar Siswa. 


\section{PENDAHULUAN}

Pendidikan merupakan hal yang sangat penting bagi semua orang. Karena melalui pendidikan dapat diciptakan sumber daya manusia (SDM) yang berkualitas dan berdaya saing yang tinggi. Pendidikan merupakan kunci utama dari perkembangan suatu negara. Gambaran tentang peningkatan kualitas sumber daya manusia Indonesia telah diupayakan oleh pemerintah dalam hal ini Kementrian Pendidikan Nasional, salah satunya dengan penyempurnaan kurikulum. Undangundang sistem Pendidikan Nasional No. 20 Tahun 2003 menyatakan bahwa pendidikan merupakan usaha sadar dan terencana untuk mewujudkan suasana belajar dan proses pembelajaran agar peserta didik secara aktif mengembangkan potensi dirinya untuk memiliki kekuatan spiritual, keagamaan, pengendalian diri, kepribadian kecerdasan, akhlak mulia, serta keterampilan yang diperlukan dirinya, masyarakat, bangsa dan negara.

Pendidikan yang bermutu ditentukan oleh beberapa faktor. Salah satunya adalah faktor pendidik. Kemampuan professional pendidik sangat perlu diperhatikan dalam rangka meningkatkan kualitas pendidikan. Pendidik sebagai pengelolah pembelajaran berperan dalam menciptakan situasi pembelajaran yang tepat sehingga memungkinkan terjadinya proses pengalaman belajar pada peserta didik. Sejalan dengan hal tersebut seorang pendidik diharapkan memiliki kemampuan dalam memilih sekaligus menggunakan model yang tepat dalam pelaksanaan pembelajaran. Penggunaan model yang tepat akan membantu tercapainya pembelajaran yang optimal.

Pembelajaran yang baik adalah pembelajaran yang mampu membuat siswa belajar mendapatkan ilmu pengetahuan dan pengalaman dengan usaha sendiri. Untuk membantu proses pembelajaran yang optimal, maka pendidik harus berupaya untuk menemukan solusi atau suatu cara dalam proses pembelajaran. Salah satu alternatif yang dapat mendukung proses belajar yang baik adalah guru perlu melakukan pembenahan dalam proses pembelajaran, mempromosikan guru sebagai perancang dan organisator pembelajaran sehingga siswa memperoleh kesempatan untuk memahami dan memaknai melalui aktivitas belajar tersebut.

Untuk itu, dalam proses pembelajaran di kelas harus mampu mengaktifkan siswa selama proses pembelajaran dan mengurangi kecenderungan guru untuk mendominasi proses . pembelajaran tersebut, sehingga ada perubahan dalam hal pembelajaran yaitu pembelajaran yang berpusat pada guru sudah sewajarnya diubah menjadi berpusat pada siswa. Untuk melakukan itu perlu disusun model pembelajaran dan dicarikan alternatif yang dapat memperbaiki pembelajaran tersebut. Salah satu alternatif yang dapat dipilih yakni model pembelajaran Reciprocal teaching dengan Model pembelajaran STAD. Model pembelajaran Reciprocal Teaching merupakan suatu model pembelajaran terbalik dimana siswa diberikan kesempatan untuk mengajarkan temannya seperti seorang guru. Dalam model pembelajaran recipcoral teaching menerapkan empat strategi pemahaman mandiri, yaitu menyimpulkan bahan ajar, menyusun pertanyaan dan menyelesaikannya, menjelaskan kembali pengetahuan yang telah diperolehnya, kemudian memprediksi pertanyaan selanjutnya dari persoalan yang diberikan pada siswa.

Model pembelajaran Reciprocal Teaching merupakan model pembelajaran yang sangat fleksibel dan mudah disesuaikan dengan kondisi kelas serta subjek pelajarannya (Yunita, 2012: 139). Hal ini berdasarkan asumsi bahwa pengetahuan dan pemahaan merupakan hasil sosialisasi kreatif yang disusun melalui proses negosiasi antara siswa dan guru atau sebaliknya. Manfaatnya adalah meningkatkan antusias siswa dalam pembelajaran karena siswa dituntut aktif berdiskusi dan menjelaskan hasil pekerjaannya dengan baik sehingga meningkatkan berpikir. Selain model Reciprocal Teaching model yang cocok untuk meningkatkan kemandirian dan motivasi belajar siswa yaitu model Student STAD. Model pembelajaran STAD (Student Team Achievement Division) dikembangkan oleh Robert Slavin dan teman-temannya di Universitas John Hopkin (dalam Rusman, 2017: 305). Dalam model pembelajaran STAD 
siswa akan belajar bersama dalam memecahkan masalah di kelompoknya. Model pembelajaran STAD menekankan pada adanya aktivitas dan interaksi diantara siswa untuk saling memotivasi dan saling membantu anggota kelompok dalam menyelesaikan suatu masalah.

Penggunaan dua model pembelajaran di atas akan mengarahkan siswa agar dapat belajar secara kelompok dan mampu belajar mandiri serta mendapatkan hasil yang baik dalam pembelajaran. Dengan berkelompok, siswa mampu bertanggung jawab atas tugas masing-masing dan bertanggung jawab kepada kelompoknya. Karena belajar secara mandiri, siswa dapat menggali dan memperdalam materi dengan caranya sendiri malalui fasilitas yang ada di sekolah. Berdasarkan pengamatan di SMP Negeri 17 Malang, hasil belajar IPS siswa kelas VII belum maksimal. Hal ini terbukti dengan nilai ulangan pada mata pelajaran IPS siswa kelas VII terdapat siswa yang nilainya di bawa nilai KKM (Kriteria Ketuntasan Minimal) yaitu $\leq 75$. Sementara KKM yang digunakan di SMP Negeri 17 Malang adalah 75. Selain itu, pembelajaran di kelas lebih banyak bersifat teacher centered. Dengan memperoleh hasil belajar IPS yang masih banyak di bawa KKM menunjukan bahwa proses pembelajaran IPS di SMP Negeri 17 Malang masih kurang efektif, sehingga dibutuhkan perubahan dari teacher centered menjadi student centered.

Dari beberapa uraian di atas, peneliti terpaku untuk membuktikan sendiri model pembelajaran manakah yang lebih tinggi hasil belajar siswa, antara model pembelajaran Reciprocal Teaching dengan model pembelajaran STAD. Oleh karena itu judul yang diambil oleh peneliti dalam penelitian ini adalah "Perbandingan Penggunaan Model Pembelajaran Reciprocal Teaching Dengan Model Pembelajaran STAD Dilihat Dari Hasil Belajar IPS Siswa Kelas VII SMP Negeri 17 Malang"

\section{TINJAUAN PUSTAKA}

Pembelajaran IPS adalah penyederhanaan atau adaptasi dari disiplin ilmu-ilmu sosial dan humaniora, serta kegiatan dasar manusia yang diorganisasikan dan disajikan secara ilmiah dan pedagogis/psikologis untuk tujuan pendidikan, Somantri dalam Sapriya (2012: 11). Terdapat beberapa model pembelajaran yang memberikan kesempatan peserta didik untuk aktif belajar mandiri salah satunya adalah model Reciprocal Teaching dan model STAD. Menurut Soimin (2014:153) model Reciprocal Teaching adalah model pembelajaran berupa kegiatan mengajar materi kepada teman. Pada model pembelajaran ini siswa berperan sebagai "guru" untuk menyampaikan materi kepada teman-temannya. Sementara itu, guru berperan sebagai fasilitator dan pembimbing yang melakukan scaffolding. Scaffolding adalah bimbingan yang diberikan oleh orang yang lebih paham kepada orang yang kurang memahami atau belum tahu Trianto (2011: 173) mengatakan bahwa: Reciprocal Teaching (Pengajaran terbalik) merupakan pendekatan konstruktivis yang berdasar pada prinsip-prinsip pembuatan/pengajuan pertanyaan".

Keterampilan-keterampilan metakognitif diajarkan melalui pengajaran langsung dan pemodelan oleh guru untuk memperbaiki kinerja membaca siswa yang membaca pemahamannya rendah. Menurut Palinscar dan Brown (2008: 117) karakteristik dari Reciprocal Teaching adalah 1) Dialog antar peserta didik dan guru, dimana masing-masing mendapat giliran untuk memimpin diskusi, (2) "Reciprocal" artinya suatu interaksi dimana seseorang bertindak untuk merespon yang lain, 3) Dialog yang terstruktur dengan menggunakan empat strategi, yaitu: merangkum, membuat pertanyaan dan jawaban, serta mengklarifikasi (menjelaskan kembali), dan memprediksi. Masingmasing strategi tersebutdapat membantu peserta didik membangun pemahaman terhadap apa yang sedang dipelajarinya.

Model STAD (Student Teams Achievement Divisions) sangat menarik untuk diterapkan dalam proses pembelajaran. Menurut Slavin (dalam Rusman, 2017: 305) tipe ini dikembangkan oleh Slavin, dan merupakan salah satu tipe kooperatif yang menekankan pada adanya aktivitas dan interaksi diantara siswa untuk saling memotivasi dan saling membantu dalam menguasai materi 
pelajaran guna mencapai hasil dan prestasi yang maksimal dalam pembelajaran. Sedangkan menurut Huda, (2015:201) dalam model pembelajaran STAD siswa akan belajar bersama memecahkan masalah dalam pembelajaran bersama kelompoknya.

\section{METODE}

Penelitian ini mengacu pada pendekatan penelitian kuantitatif. Jenis penelitian yang digunakan pada penelitian ini yaitu penelitian Quasi Eksperimental Design. Cara untuk mengetahuinya yaitu membandingkan satu atau lebih kelompok eksperimen yang diberi treatment dengan satu kelompok pembanding yang tidak diberi treatment. untuk lebih jelasnya perhatikan skema Non-Equivalent Control Group Design. Skema desain penelitian ini dapat di;ihat pada table dibawa ini:

Tabel 3.1 Skema Non-Equivalent Control Group Design

\begin{tabular}{|l|c|c|c|}
\hline \multicolumn{1}{|c|}{ Kelas } & Pretest & Perlakuan & Posttest \\
\hline $\begin{array}{l}\text { Kelas } \\
\text { eksperimen } \\
\text { (Reciprocal } \\
\text { Teaching) }\end{array}$ & ${ }^{\mathrm{T}} 1$ & ${ }^{\mathrm{x}} 1$ & \\
\hline $\begin{array}{l}\text { Kelas } 2 \\
\text { Ekksperimen } \\
\text { (STAD) }\end{array}$ & & & \\
\hline
\end{tabular}

Penelitian ini melibatkan dua kelas yaitu kelas eksperimen I dan kelas eksperimen II yang diberi perlakuan berbeda. Pada kedua kelas diberikan materi yang sama untuk mengetahui kemampuan hasil belajar IPS siswa diperoleh dari penerapan dua perlakuan tersebut.

\section{PEMBAHASAN}

Deskripsi data dalam penelitian ini adalah perbandingan penggunaan model pembelajaran Reciprocal Teaching dan STAD dilihat dari hasil belajar IPS siswa kelas VII SMP Negeri 17 Malang. Uraian deskripsi dilakukan dengan menganalisis data pre-test dan post-test pada kelas eksperimen I dan eksperimen II. Pada kelas eksperimen I, rata-rata nilai pre-test siswa sebesar 47,79. Setelah diberikan perlakuan (treatment) dengan model reciplocal teaching, rata-rata nilai post-test siswa meningkat menjadi 79,91. Pada kelas eksperimen II, rata-rata nilai pre-test siswa sebesar 49,29. Setelah diberikan perlakuan (treatment) dengan model STAD, rata-rata nilai post-test siswa meningkat menjadi 74.53 .

\section{Model Pembelajaran Reciprocal Teaching Terhadap Hasil Belajar Siswa Pada Mata Pelajaran IPS}

Penelitian ini bertujuan untuk mengetahui perbedaan penggunaan model Reciprocal Teaching dengan model STAD dilihat dari hasil belajar IPS siswa kelas VII SMP Negeri 17 Malang. dari hasil penelitian menunjukan bahwa hasil belajar yang menggunakan model reciplocal teaching dari hasil prestest ke posttest mengalami pengingkatan atau terdapat perbedaan. Hal ini dapat ditunjukan dengan rata-rata hasil pretest yaitu 47.79 dan rata-rata hasil posttest atau setelah mendapatkan perlakuan model pembelajaran reciplocal teaching adalah 79.09.

\section{Model Pembelajaran STAD Terhadap Hasil Belajar Siswa Pada Mata Pelajaran IPS}

Temuan dari hasil penelitian menunjukan bahwa hasil belajar yang menggunakan model STAD dari hasil prestest ke posttest mengalami pengingkatan atau terdapat perbedaan. Hal ini dapat ditunjukan dengan rata-rata hasil pretest yaitu 49.29 dan rata-rata hasil posttest atau setelah mendapatkan perlakuan model pembelajaran STAD adalah 74.53. Meskiun model STAD mengalami peningkatan antara hasil pretest dan posttest dalam pembelajaran, namun model tersebut tidak 
sebanding dengan hasil pretest dan posttest model reciplocal teaching yang lebih tinggi dalam meningkatkan hasil belajar.

\section{Perbedaan Hasil Belajar siswa pada Mata Pelajaran IPS Yang Menggunakan Model Reciprocal Teaching Dengan Model STAD}

Berdasarkan hasil uji hipotesis atau uji-t dan analisis data mengenai perbedaan penggunaan model pembelajaran Reciprocal Teaching dan model pembelajaran STAD terhadap hasil belajar IPS kelas VII SMP Negeri 17 Malang didapatkan temuan penelitian yaitu terdaapat perbedaaan hasil belajar IPS dengan menggunakan model Reciprocal Teaching dengan model pembelajaran STAD pada siswa kelas VII SMP Negeri 17 Malang. Perbedaan tersebut telah dibuktikan dengan melakukan uji hipotesis atau uji-t, namun sebelum melakukan pengujian hipotesis terlebih dahulu melakukan uji normalitas dan uji homogen data penelitian. Hasil uji normalitas berdasarkan tabel kolmogorow smirow yang diperoleh dari hasil output SPSS16.0 for windows dapat diketahui bahwa nilai kelas eksperimen I Sig >0,05 yaitu .165 sehingga dapat disimpulkan bahwa data yang diperoleh berdistribusi normal. untuk kelas eksperimen II Sig > 0,05 yaitu .127 dapat disimpukan bahwa data yang diperoleh berdistribusi normal. Setelah semua data dikatakan normal, langkah selanjutnya adalah uji homogenitas. kelas yang digunakan adalah kelas VII E dan VII G. Kelas VII E sebagai kelas eksperimen I menggunakan model Reciprocal Teaching dalam pembelajaran IPS, sedangkan VII G sebagai kelas eksperimen II menggunakan model pembelajaran STAD dalam pembelajaran IPS.

Untuk mengetahui apakah ada perbedaan hasil belajar yang signifikan atau tidak antara kelas eksperimen I dan eksperimen II, maka dilakukan pengujian hipotesis atau uji-t. Namun sebelum melakukan uji-t, terlebih dahulu melakukan uji normalitas dan uji homogen data dari hasil penelitian. Dari hasil uji normalitas data yang dilakukan terdapat hasil yang diketahui bahwa kelas eksperimen I Sig yaitu .165>0,05 sehingga data yang diperoleh berdistribusi normal. untuk kelas eksperimen II Sig yaitu .127>0,05 sehingga data yang diperoleh berdistribusi normal. Selanjutnya dari hasil uji homogen diketahui bahwa kelas eksperimen I dan II sig yaitu .526 >0,05 sehingga dapat disimpulkan bahwa data yang diperoleh terdapat kesamaan atau homogen antar kelas yang akan diuji. Hasil uji-t menyatakan bahwa nilai thitung pada post-test antara kelas eksperimen I dan eksperimen II adalah 2.458 dengan signifikasi nilai 5\% ditemukan hasil thitung $3.046>$ ttabel 1.6682 . Dari analisis di atas, terbukti bahwa terdapat perbedaan yang signifikan penggunaan model reciplocal teaching dengan STAD dilihat dari hasil belajar IPS siswa kelas VII SMP Negeri 17 Malang.

Berdasarkan hasil penelitian menunjukkan bahwa hasil belajar siswa dalam pembelajaran IPS di SMP Negeri 17 Malang dengan menggunakan model pembelajaran Reciprocal Teaching lebih tinggi dari pada hasil belajar siswa yang menggunakan model pembelajaran STAD. Perbedaan ini dimungkinkan karena kedua model memiliki perbedaan karakteristik dan proses yang berlangsung dalam pembelajaran IPS juga berbeda. Pembelajaran Reciprocal Teaching terbukti dapat meningkatkan kemampuan berpikir kreatif IPS siswa, indikator utama penyebab dari keberhasilan dari pembelajaran ini lebih banyak melibatkan siswa dalam proses pembelajaran, siswa lebih aktif pada saat pembelajaran, dalam proses pembelajaran siswa dituntut untuk menyelesaikan masalah sendiri, didorong untuk berfikir agar mendapatkan solusi untuk memecahkan masalah yang diberi, lalu siswa tersebut berdiskusi kepada pasangannya dan berbagi kepada teman sekelas, di tahap ini siswa yang semula pasif akan terdorong untuk ikut serta dalam setiap kegiatan pembelajaran yang disajikan oleh guru, tidak hanya duduk diam, dan mendengarkan, dengan siswa lebih aktif dan ikut serta dalam proses pembelajaran siswa akan lebih mudah memahami materi yang diajarkan dan lebih mengingat materi pelajaran baik dalam bentuk konsep, langkah-langkah penyelesaian dari suatu masalah, dan lain-lain. Sedangkan model pembelajaran STAD, siswa dalam kelompok dapat saling mendukung dan membantu satu sama lain dalam menguasai kemampuan yang diajarkan oleh guru. Siswa akan lebih aktif dalam proses pembelajaran dikarenakan mereka akan berusaha satu sama lain dalam memperoleh skor tertinggi bagi timnya. Hal tersebut yang menyebabkan hasil 
belajar siswa di kelas yang menggunakan model pembelajaran reciplocal teaching dengan model STAD berbeda.

\section{KESIMPULAN}

Berdasarkan hasil penelitian yang dilakukan dan juga hasil analisis yang diperoleh dapat disimpulkan terdapat perbedaan hasil belajar IPS antara siswa yang diajarkan mengsgunakan model Reciprocal Teaching dengan STAD pada siswa kelas VII SMP Negeri 17 Malang. Hal ini ditunjukan dengan nilai rata-rata posttest hasil belajar yang mengikuti pembelajaran IPS dengan menggunakan model Reciprocal Teaching pada kelas eksperimen I lebih tinggi dibandingkan nilai rata-rata posttest hasil belajar siswa yang mengikuti pembelajaran IPS yang menggunakan model STAD.

\section{DAFTAR PUSTAKA}

Arikunto, Suharsimi. 2010. Prosedur penelitian suatu pendekatan praktik. Jakarta: Rineka Cipta

Astuti, S. Endang. 2010. Bahan Dasar untuk Pelayanan Konseling pada Satuan Menengah. Jilid 1.

Grasindo. Jakarta

Depdiknas. 2013. Undang-undang RI No.20 Tahun 2003. Tentang sistem pendidikan nasional.

Desmita. 2014. Psikologi Perkembangan Peserta Didik. Bandung: PT Remaja Rosdakarya.

Fathurrohman, Muhammad. (2015). Model- model Pembelajaran Inovatif. Yogyakarta: Ar-ruzz Media

Hamiyah, Nur, dkk. 2014. Strategi dan belajar mengajar di kelas. Prestasi. Pustajkaraya: Jakarta.

Huda, M. 2015. Model-Model pengajaran dan pembelajaran. Yogyakarta: Pustaka Belajar.

Majid A. 2013. Strategi Pembelajaran. Bandung : Remaja Rosdakarya

Mulyoto, Effendi Hasan, Nur, E. Suryani, N. 2013. Jurnal Teknologi Pendidikan. 1(2): 214225.

Rusman, 2017. Belajar dan pembelajaran berorientasi standar proses pendidikan. Jakarta: Kencana

Rusmono. (2012). Strategi Pembelajaran dengan Problem Based Learning. Bogor: Ghalia Indonesia.

Sapriya, 2012. Pendidikan IPS, Konsep dan pembelajaran. Bandung. Rosdakarya

Sardiman. 2016. Interaksi dan Motivasi Belajar Mengajar. Raja Wali Pers.

Shoimin A, 2014. Model pembelajaran inovatif dalam kurikulum 2013. Yogyakarta: AR RUZZ MEDIA

Sugiyono. 2011. Metode Penelitian Kuantitatif, kualitatif dsn RED. Bandung: Alfabeta.

Sugiyono. 2013. Metode Penelitian Pedidikan Kuantitatif, Kualitatif, dan RED. Bandung: Alfabeta

Sumarmo, U. 2004. Kemandirian Belajar: Apa, Mengapa, dan Bagaimana Dikembangkan Pada peserta

Didik. Dalam Prosiding Seminar Nasional. 27 November 2010: FMIPA Universitas Negeri

Yogyakarta.

Suprihatiningrum J. (2014). Strategi Pembelajaran. Jogjakarta: Ar-ruzz Media.

Suprijono, A. 2010. Cooperative Learning. Yogyakarta. Pustaka Media

Trianto, 2011. Model Pembelajaran Terpadu Konsep,Strategi Dan Implementasinya Dalam Kurikulum Tingkat Satuan Pendidikan (KTSP), Jakarta : Bumi Aksara 